\title{
ORGANIZAÇÃO DO ACESSO E PERMANÊNCIA DAS PESSOAS COM DEFICIÊNCIA NO ENSINO SUPERIOR A PARTIR DA INSTAURAÇÃO DO PROGRAMA INCLUIR
}

\author{
ORGANIZACIÓN DEL ACCESO Y PERMANENCIA DE LAS PERSONAS CON \\ DISCAPACIDAD EN LA ENSEÑ ANZA SUPERIOR A PARTIR DE LA \\ INSTAURACIÓN DEL PROGRAMA INCLUIR
}

\author{
ORGANIZATION OF ACCESS AND PERMANENCE OF PEOPLE WITH \\ DISABILITIES IN HIGHER EDUCATION FROM THE INSTAURATION OF THE \\ INCLUIR PROGRAM
}

\author{
Patricia Tanganelli LARA ${ }^{1}$ \\ Eladio SEBASTIÁN-HEREDERO ${ }^{2}$
}

RESUMO: O Programa Incluir influenciou as políticas institucionais, para a implementação de ações de acessibilidade para pessoas com deficiência no ensino superior, em todos os estados brasileiros. Com o apoio financeiro do MEC, as universidades do Brasil criaram e/ou reestruturaram os núcleos de acessibilidade nas Instituições Federais de Ensino Superior e Instituições Estaduais de Ensino Superior. Assim, o objetivo desse trabalho é analisar como está a situação atual a partir das produções de teses e dissertações, desde sua publicação, para compreender como as Instituições de Ensino Superior estão se organizando para apoiar o ingresso e a permanência de pessoas com deficiência, após esse aporte financeiro e as publicações das políticas públicas de inclusão no Brasil. Os procedimentos metodológicos dessa pesquisa são de caráter qualitativo e bibliográfico por meio da análise de conteúdo sobre o tema. Os resultados desse período investigado revelaram o avanço da implementação das políticas públicas, após 2005, com a criação dos núcleos de acessibilidade e os apoios para a inclusão de jovens e adultos com deficiência, contudo foi possível identificar a necessidade da formação docente e dos profissionais que atuam nestas instituições para eliminar as barreiras atitudinais e comunicacionais encontradas em muitas instituições de ensino superior.

PALAVRAS-CHAVE: Inclusão. Ensino superior. Deficiência. Educação especial.

RESUMEN: El Programa Incluir influenció las politicas institucionales, para la implementación de acciones de accesibilidad para personas con deficiencia en la enseñanza superior, en todos los estados brasileños. Con el apoyo financiero del MEC, las universidades de Brasil crearon y/ o reestructuraron las unidades de apoyo a la diversidad en las Instituciones Federales de Enseñanza Superior e Instituciones Estatales de Enseñanza Superior. Así, el objetivo de este trabajo es analizar cómo está la situación actual a partir de

\footnotetext{
${ }^{1}$ Universidade Federal de Mato Grosso do Sul (UFMS), Campo Grande - MS - Brasil. Pós-Doutoranda no Programa de Pós-Graduação em Educação. ORCID: https://orcid.org/0000-0002-4616-4452. E-mail: patriciatanganelli@gmail.com

${ }^{2}$ Universidad de Alcalá (UAH), Madri - Espanha. Professor Visitante Estrangeiro (UFMS). Doutorado em Educação (UAH) - Espanha. Pós-Doutorado em Educação (UNESP). ORCID: http://orcid.org/0000-0003-02934395. E-mail: eladio.sebastian@gmail.com
}

RPGE- Revista on line de Política e Gestão Educacional, Araraquara, v. 24, n. esp. 2, p. 1137-1164, set. $2020 . \quad$ e-ISSN:1519-9029 DOI: https://doi.org/10.22633/rpge.v24iesp2.14337 
las producciones de tesis y disertaciones de maestría, desde su publicación, para comprender como estas instituciones de Enseñanza Superior se han organizando para apoyar el ingreso e la permanencia de personas con discapacidad, después de ese aporte financiero y las publicaciones de las políticas públicas de inclusión en Brasil. Los procedimientos metodológicos de esta pesquisa son de carácter cualitativo y bibliográfico usando el análisis de contenido. Los resultados de este periodo investigado revelaron el avance en la implementación de las políticas públicas, después de 2005, con la creación de las unidades de apoyo a la diversidad y los recursos para la inclusión de jóvenes y adultos con discapacidad, además fue posible identificar la necesidad de la formación docente y de los profesionales que trabajan en estas instituciones para eliminar las barreras actitudinales y comunicativas localizadas en muchas instituciones de enseñanza superior.

PALABRAS CLAVE: Inclusión. Enseñanza superior. Discapacidad. Educación especial.

ABSTRACT: The Incluir Program influenced institutional policies for the implementation of accessibility actions for people with disabilities in higher education, in all Brazilian states. With financial support from the MEC, Brazilian universities created and/or restructured diversity support units in Federal Institutions of Higher Education and State Institutions of Higher Education. Thus, the objective of this work is to analyze how the current situation is, from the productions of theses and master's thesis, since their publication, to understand how these Higher Education institutions have organized to support the entry and permanence of people with disabilities after this financial contribution and the publications of the inclusion public policies in Brazil. The methodological procedures of this research are qualitative and bibliographic in nature, using content analysis. The results of this investigated period revealed progress in the implementation of public policies, after 2005, with the creation of diversity support units and resources for the inclusion of young people and adults with disabilities, it was also possible to identify the need for teacher formation and for professionals working in these institutions to eliminate the attitudinal and communication barriers located in many higher education institutions.

KEYWORDS: Inclusion. Higher education. Disability. Special education.

\section{Introdução}

No Brasil, o reflexo das declarações internacionais foi decisivo para a implementação de políticas públicas de acesso, para pessoas com deficiência no ensino superior. Pletsch e Leite (2017, p. 88) afirmam que desde os anos 1990, "os direitos sociais e educacionais de pessoas com deficiência têm figurado nos debates nacionais e internacionais", tendo no ensino superior se apresentado como espaço da pluralidade, da diversidade e do respeito às diferenças. A primeira década do século XXI, no Brasil, foi abalizada por ações afirmativas, com o reconhecimento da garantia de direitos, como um paradigma social e um processo crescente de adoção de estratégias de apoio para a qualidade de ensino para todos e todas. 
O Conselho Nacional de Educação, através dos Pareceres n. ${ }^{\circ}$ 17, de 2001 e nº 4, de 2002, e Resolução $n^{\circ} 2$ de 2001, apresenta as diretrizes da perspectiva da educação inclusiva, fixando as diretrizes curriculares nacionais, orientando os sistemas educacionais e estabelecimentos quanto aos procedimentos a serem adotados, cabendo às instituições de ensino a organização do atendimento às necessidades das pessoas com deficiência.

Apesar de essa Resolução apresentar um caráter mais inclusivo, em seu Artigo $9^{\circ}$, possibilita que escolas possam criar, extraordinariamente, classes especiais, assim, Bueno (2011, p. 163) ressalta que

[...] a legislação e as normas em vigor no país procuraram dar relevo à inclusão escolar de aluno com deficiência, mas que, prudentemente, deixam abertos espaços para a não inclusão, procurando estabelecer limites às formas segregadas de ensino.

A repercussão da inclusão das pessoas com deficiência estava mais centrada na educação básica, nos apoios para a permanência, e a percepção dos limites da escolarização para todos.

O Decreto $n^{\text {o }}$ 5.296/ 2004 (BRASIL, 2004), regulamenta as condições para a implementação de política nacional de acessibilidade e no Artigo 24, determina que os estabelecimentos de ensino de qualquer nível, etapa ou modalidade, público e privado, proporcionem condições de acesso e utilização dos seus ambientes ou compartimentos por pessoas com deficiência ou com mobilidade reduzida, inclusive salas de aula, biblioteca, auditórios, instalações desportivas, laboratórios, áreas de lazer e sanitários.

Nesse sentido, houve a implementação do Programa INCLUIR do Governo Federal em 2005, destinado à Educação Superior, visando desenvolver a política de acessibilidade às pessoas com deficiência. O programa disponibilizou apoio financeiro do MEC, para as propostas de universidades do Brasil inteiro, para apoiar projetos de criação ou reestruturação de núcleos de acessibilidade nas Instituições Federais de Ensino Superior e Instituições Estaduais de Ensino Superior.

O Programa INCLUIR foi executado em chamadas públicas entre 2005 e 2011 para a implementação de ações de acesso e permanência de pessoas com deficiência nas Instituições públicas de ensino superior, para a identificação das barreiras e a garantia do acesso. Em 2012 houve um aporte de recurso financeiro diretamente na matriz orçamentária das Universidades Federais, para esse objetivo em função do número de alunos com deficiência matriculados nas instituições.

As ações de acessibilidade referentes ao Programa INCLUIR estavam: 
- Adequação arquitetônica para acessibilidade nos diversos ambientes das IES. Adequações: rampas, barras de apoio, corrimão, piso e sinalização tátil, sinalizadores, alargamento de portas e vias, instalação de elevadores, etc.

- Aquisição de recursos de tecnologia assistiva para a promoção da acessibilidade pedagógica nas comunicações e informações aos estudantes com deficiência e demais membros da comunidade universitária. Materiais: computadores com interface de acessibilidade, impressoras em braile, linhas braile, lupas eletrônicas, teclados colmeia com acionadores acessíveis, etc.

- Aquisição e desenvolvimento de materiais didáticos e pedagógicos acessíveis;

- Aquisição e adequação de mobiliários para acessibilidade;

- Formação de profissionais para o desenvolvimento de práticas educacionais inclusivas e para o uso dos recursos de tecnologia assistiva, da Língua Brasileira de Sinais - Libras e outros códigos e linguagens. (BRASIL, 2013).

Garcia e Michels (2011) ao analisar a política de educação especial no Brasil, no período de 1991 - 2011, citando o Programa Incluir, as autoras consideram que:

o fato de a política educacional ter sofrido uma inserção de conceitos e de ações relacionadas à ideia de inclusão não tornou o espaço educacional mais democrático. A gestão por editais tem apresentado definições políticas para o setor, induzindo uma adesão ao modelo assumido no projeto do governo federal. A relação proposta entre unidade escolar executora e órgão gestor dos atendimentos especializados em cada sistema de ensino representa uma forma descentralizada de administração. Esse modelo desloca das tarefas executivas de implementação de políticas para os níveis locais ao mesmo tempo em que mantém processos centralizados de controle da gestão. A relação proposta entre unidade escolar executora e o setor responsável pela coordenação dos atendimentos especializados em cada sistema de ensino, nestes termos, remete para um modelo no qual quem está no "centro" regula, via orientações e avaliações, as ações de quem está na "ponta", executando as políticas (p. 114).

O movimento de organização das ações de inclusão de pessoas com deficiência demanda um processo de debate político dos diferentes setores para que as ações sejam implementadas conforme as necessidades do público-alvo da educação especial.

Finalmente, em 2008, o Ministério da Educação institui a Política Nacional de Educação Especial na Perspectiva Inclusiva. O documento especifica o público-alvo dessa política e estabelece o Atendimento Educacional Especializado para o sucesso da inclusão escolar, por meio de apoio de professores especializados e sala de recursos multifuncionais ou em Centros de Atendimento Educacional Especializado. 
Essa política de inclusão tem refletido, significativamente, no ingresso de pessoas com deficiência no ensino superior, assim o Decreto $n^{0}$ 7.611/11 (BRASIL, 2011) dispõe sobre o Atendimento Educacional Especializado e a estruturação de núcleos de acessibilidade nas instituições federais de Educação Superior, visando eliminar barreiras atitudinais, físicas e comunicacionais, que restringem a participação e o desenvolvimento acadêmico e social de estudantes com deficiência.

A publicação de leis e decretos garante o direito de todas as pessoas com deficiência de ocupar espaços antes não considerados como possível. Assim Ferreira e Duarte (2010, p. 19) consideram que "as leis, certamente, representam uma conquista pelo fundamental direito humano de essas pessoas serem reconhecidas como diferentes enquanto seres biológicos e sociais, mas nem por isso desiguais enquanto cidadãos".

No Censo da Educação Superior, publicada pelo Instituto Nacional de Estudos e Pesquisas Nacionais Anísio Teixeira (INEP), em 2018 era de 43.633, esse número significa $0.52 \%$ em relação ao total de matrícula em cursos de Graduação, como segue:

Figura 1 - Gráfico do Número de matrículas em cursos de graduação de alunos PAEE, por tipo de deficiência - Brasil 2018

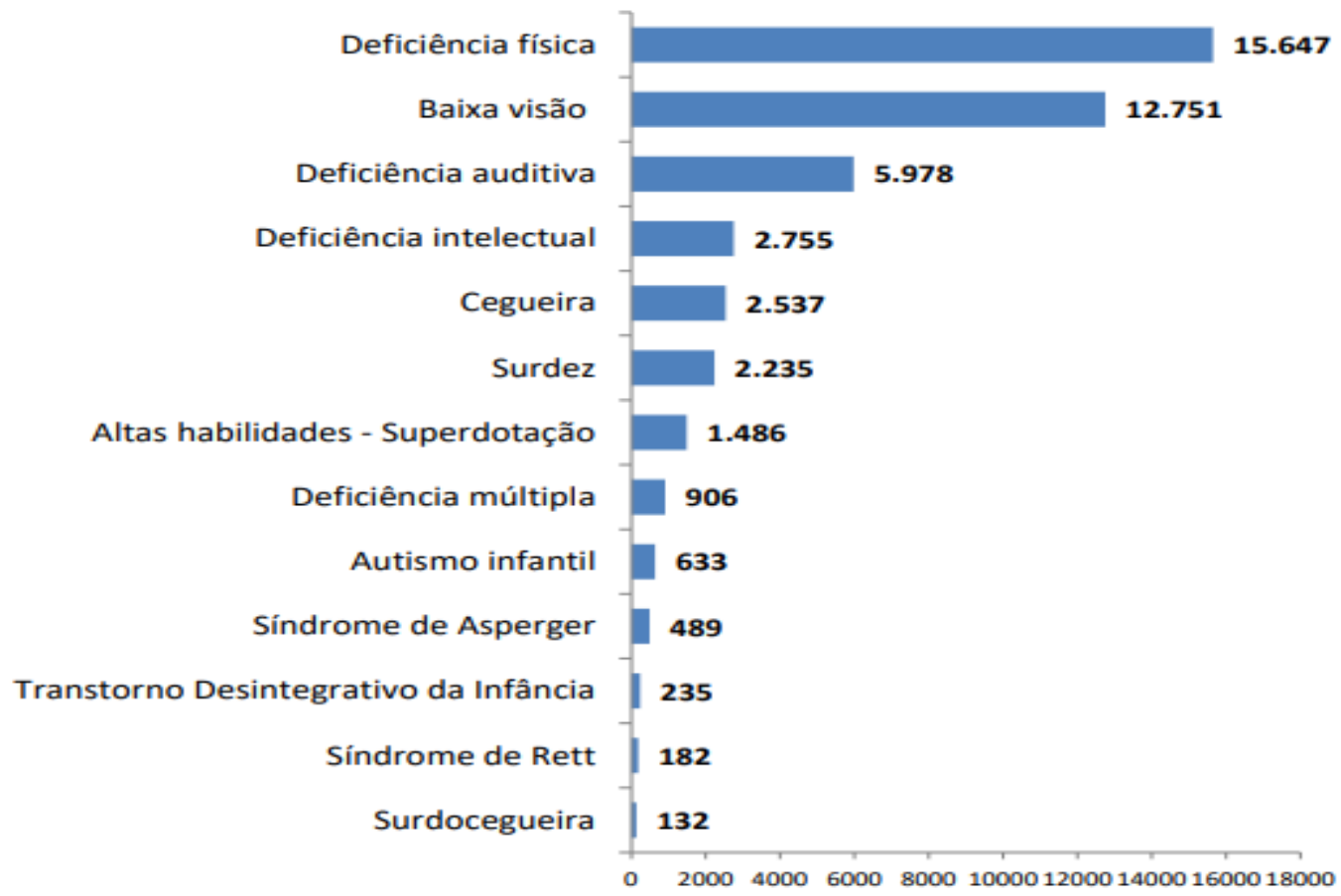

Fonte: INEP (2018)

Esses números indicam a necessidade de políticas públicas e institucionais como os Núcleos de Acessibilidade nas instituições de ensino superior, para o acesso das pessoas com 
deficiência, contudo os desafios permanecem, pela necessidade de formação de toda a equipe acadêmica para o apoio desse público específico, principalmente aqueles que precisam de um plano específico para a permanência.

Além dos Núcleos de Acessibilidade, algumas Universidades Públicas do Brasil adotaram o sistema de cotas para democratizar o ingresso no ensino superior no início da década de 2000. O público-alvo dessa política são pessoas com deficiência, afrodescendentes, indígenas, estudantes que vieram de rede pública de ensino e jovens de baixa renda.

Por meio das discussões sobre cotas, as universidades públicas do Brasil, foram aumentando e reservando uma porcentagem de suas vagas para pessoas com deficiência, normalmente 5\% das vagas são reservadas para estudantes público-alvo da Educação Especial.

Houve, também, um aumento dos repasses pelo Governo Federal, por meio do Programa de Apoio a Planos de Reestruturação e expansão das Universidades Federais - REUNI, criado pelo Decreto $n^{\circ}$ 6.096/07 (BRASIL, 2007), com o objetivo de aumentar o número de vagas nas universidades públicas.

Assim, os programas: INCLUIR, REUNI, SISU, PROUNI e FIES são considerados políticas afirmativas de acesso ao ensino superior, e seguem com normatizações do Governo Federal para a adesão pelas Instituições de Ensino Superior. A mobilização das universidades com ações para o ingresso de pessoas com deficiência tem repercutido no cotidiano das IES, em sua responsabilidade para a formação docente e de recursos humanos para o acolhimento e atendimento dessa demanda.

Para tanto, esse artigo apresenta a organização que está sendo feita pelas IES para o acesso e permanência na inclusão de pessoas com deficiência no ensino superior. Esse recorte temporal se fundamenta por revelar o reflexo da política implementada em 2005, pelo Programa INCLUIR, no Ensino Superior e a publicação da Política Nacional de Educação Especial na Perspectiva da Educação Inclusiva de 2008. O objetivo é mapear e analisar as produções de teses e dissertações para compreender como as Instituições de Ensino Superior estão se organizando para apoiar o ingresso e a permanência de pessoas com deficiência.

Sebastián-Heredero (2019) considera que uma instituição de ensino inclusiva nunca está totalmente construída, sendo um processo que precisa da colaboração de todos e somente com ações planejadas em longo prazo, se pode chegar a completar. Assim, esse trabalho se justifica pela necessidade de compreender como os processos foram implementados nas Instituições de Ensino Superior e como a organização das ações, por ela realizadas, tem refletido para a permanência dos alunos com deficiência e o sucesso da inclusão. 


\section{Metodologia}

Para realizar a análise sobre o conhecimento acumulado acerca da temática do estudo, estabeleceu-se, como fonte de consulta, a Biblioteca Digital Brasileira de Teses e Dissertações (BDTD - IBICT) e o Banco de Teses e Dissertações da Coordenação de Aperfeiçoamento de Pessoal de Nível Superior (Capes).

Em termos procedimentais, a pesquisa de caráter qualitativo e bibliográfico com análise documental sobre o tema, procura mapear e discutir as principais tendências na área. Conforme Ferreira (2002, p. 257) o estado da arte de caráter bibliográfico, procura responder que

aspectos e dimensões vêm sendo destacados e privilegiados em diferentes épocas e lugares, de que formas e em que condições têm sido produzidas certas dissertações de mestrado, teses de doutorado, publicações em periódicos e comunicações em anais de congressos e de seminários.

Foram utilizados os seguintes descritores: "acesso e ensino superior", "pessoa com deficiência e ensino superior", "núcleo de acessibilidade e ensino superior", "público-alvo da educação especial e ensino superior”. Nesse intervalo entre 2005, data de criação do programa INCLUIR, e o ano de 2020 foram localizadas 278 trabalhos -dissertações e teses- entre a Capes e a BDTD. Utilizados os critérios de exclusão de ficar fora do foco de acesso e permanência de estudantes com deficiência no Ensino Superior, isso derivado da análise dos resumos, foram retiradas 41 teses e dissertações que atendiam aos critérios do estudo.

O quadro 1 apresenta o resultado da pesquisa de revisão bibliográfica das 8 teses $(\mathrm{T})$ e 33 dissertações (D) selecionadas conforme o ano de sua publicação onde podemos observar um incremento das publicações a partir do ano de 2015.

Quadro 1 - Teses e dissertações produzidas entre 2005 e 2019 sobre a temática inclusão de pessoas com deficiência no Ensino Superior, na Capes e na BDTD

\begin{tabular}{|c|c|c|c|c|c|c|c|c|c|c|c|c|c|c|}
\hline \multirow{2}{*}{$\begin{array}{l}\text { Tipo de } \\
\text { trabalho }\end{array}$} & \multicolumn{13}{|c|}{ Ano } & \multirow[t]{2}{*}{ total } \\
\hline & $\stackrel{\overbrace{}}{\check{\overbrace{}}}$ & 气્స & 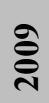 & 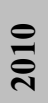 & $\overline{\bar{\nu}}$ & 굴 & $\stackrel{m}{\stackrel{4}{2}}$ & 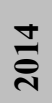 & $\stackrel{n}{\frac{1}{2}}$ & ำ & $\stackrel{ }{\stackrel{2}{*}}$ & $\stackrel{\infty}{\frac{\pi}{2}}$ & 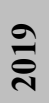 & \\
\hline Teses & & & 1 & & 2 & 1 & & & 1 & 1 & & 2 & & 8 \\
\hline $\begin{array}{c}\text { Dissertaç } \\
\text { ões }\end{array}$ & 1 & 1 & 1 & 1 & 2 & 1 & 2 & 2 & 5 & 9 & 3 & 2 & 3 & 33 \\
\hline
\end{tabular}

Fonte: Elaboração própria 
Como pode ser observado, dos 41 trabalhos que finalmente foram analisados, trinta e três são de mestrado e oito de doutorado, sendo que no ano de 2015 e 2016 teve quase a metade deles e no ano de 2019 foram apresentados três trabalhos.

A modo de curiosidade bibliométrica, observamos uma maior concentração de trabalhos nas Universidade Públicas frente às particulares, assim mesmo dos trabalhos selecionados a maioria estava nas Universidades Federais, num total de trinta e quatro, onze estavam em Universidades Estaduais e quatro em Universidades particulares.

Para a análise dos dados os trabalhos foram lidos e agrupados de acordo com as seguintes três categorias: políticas de acesso no ensino superior; suporte para a permanência e promoção de acessibilidade; percepção dos estudantes com deficiência no ensino superior derivadas por sua vez da análise de conteúdo dos resumos; embora da análise do texto das mesmas foram obtidas outras subcategorias que aparecem detalhadas nos resultados. O Quadro 2 sintetiza a as teses e dissertações por categoria.

Quadro 2 - Relação de categorias elencadas a partir da análise das teses e dissertações

\begin{tabular}{|c|c|c|}
\hline Categorias & Tipo & Autores e ano de publicação \\
\hline \multirow{2}{*}{$\begin{array}{l}\text { Políticas de acesso no } \\
\text { ensino superior }\end{array}$} & $\mathrm{T}(3)$ & Castro (2011); Góes (2015); Fiorin (2018). \\
\hline & $\mathrm{D}(13)$ & $\begin{array}{l}\text { Pereira (2007); Duarte (2009); Souza (2010); Rocha (2011); } \\
\text { Santos (2012); Sousa (2013); Galdino (2015); Silva (2016); } \\
\text { Alves (2016); Aguiar (2016); Pereira (2017); Luz (2018); } \\
\text { Chaiben (2019). }\end{array}$ \\
\hline \multirow{2}{*}{$\begin{array}{lr}\text { Suporte para } & \text { a } \\
\text { permanência } & \mathrm{e} \\
\text { promoção } & \mathrm{de} \\
\text { acessibilidade } & \end{array}$} & T (2) & Comarú (2012); Breitenbacha (2018). \\
\hline & $\mathrm{D}(11)$ & $\begin{array}{l}\text { Alencar (2013); Ciantelli (2015); Dillenburg (2015); Ribeiro } \\
\text { (2016); Santiago (2016); Santana (2016); Silva (2017); } \\
\text { Ricardo (2017); Vieira (2018); Seeger (2019); Madruga } \\
\text { (2019). }\end{array}$ \\
\hline \multirow{2}{*}{ 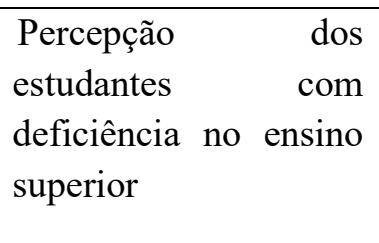 } & $\mathrm{T}(3)$ & Rosseto (2009); Guerreiro (2011); Borgamnn (2016). \\
\hline & $\mathrm{D}(9)$ & $\begin{array}{l}\text { Fortes (2005); Nascimento (2011); Tavares (2014); Sousa } \\
\text { (2014); Carvalho (2015); Torres (2015); Cruz (2016); Cruz } \\
\text { (2016); Passos (2016). }\end{array}$ \\
\hline
\end{tabular}

Fonte: Elaboração própria

Após análise do conteúdo dos trabalhos e com base nessas categorias, apresentamos as reflexões qualitativas tecidas de todas as produções, agrupadas nas categorias de analise 
preestabelecidas, que virão nos iluminar sobre a organização do acesso e permanência dos estudantes com deficiência na Educação Superior.

\section{Políticas de Acesso no Ensino Superior}

Para a discussão sobre as políticas de acesso ao ensino superior serão apresentadas, inicialmente, as teses de Castro (2011), Goes (2015) e Fiorin (2018) e em seguida as treze dissertações.

Com o objetivo de identificar as ações e iniciativas de universidades públicas brasileiras quanto ao ingresso e permanência de pessoas com deficiência, a fim de verificar as barreiras e os facilitadores encontrados pelos estudantes no cotidiano do ensino superior, Castro (2011), realizou uma pesquisa de campo em 13 universidades públicas brasileiras em oito estados do Brasil, mais o Distrito Federal. A autora identificou ações como o Atendimento Educacional Especializado, a estrutura e a organização do Departamento de apoio à Inclusão e o Núcleo de Apoio às Pessoas com Necessidades Especiais, modificações em biblioteca, guia acessível, o crescimento no número de matrícula de alunos com deficiência nas universidades, guia acessível e manual do candidato.

Todas essas ações colaboraram como o êxito acadêmico dos alunos com deficiência, conforme Castro (2011), porém ainda não suficientes. A autora identificou, por meio das entrevistas com alunos, as barreiras arquitetônicas, como a ausência de rampas; barreiras comunicacionais, como a falta de informações acessíveis e intérprete de Libras; barreiras pedagógicas, como práticas pedagógicas inadequadas ou falta de material didático adaptado e as barreiras atitudinais, sendo essas as mais citadas pelos alunos. As barreiras atitudinais, citadas por Castro (2011, p. 226) são aquelas:

[...] atitudes dos professores em sala de aula, o relacionamento com os colegas, $\mathrm{o}$ desrespeito às vagas reservadas nos estacionamentos para pessoas com deficiência, o estacionamento em frente às rampas e obstáculos nas calçadas e caminhos.

Todas as evidências localizadas por Castro (2011) indicam a necessidade de políticas públicas institucionais, discutidas por Goes (2015) ao analisar as políticas de inclusão e as condições de permanência dos alunos com deficiência na Universidade Estadual do Oeste do Paraná (UNIOESTE). Por meio de entrevistas semiestruturada com alunos com deficiência, professores, coordenadores de cursos, diretores de Campus e de Centros Institucional de Ações Relativas às Pessoas com Necessidades Especiais e gestores dos Campus da Universidade, Goes 
(2015), também identificou barreiras arquitetônicas, que a autora chama de barreiras físicas, barreiras atitudinais e sistêmicas.

A IES investigada por Goes (2015) apresenta um Programa Institucional de Ações Relativas às Pessoas com Necessidades Especiais (PEE), sendo reconhecida pelos entrevistados como uma ação afirmativa para o acesso à universidade, como as bancas do processo seletivo vestibular, porém indicaram a necessidade do repasse financeiro para a contratação de profissionais especializados para atender a demanda existente em todos os Campus da Universidade. A autora expressa a inexistência de políticas de permanência na IES, como a distribuição de bolsa de estudos, como um suporte para o aluno com deficiência. As barreiras sistêmicas apresentadas por Goes $(2015$, p. 218) são descritas como a carência de serviços assistivos, tais como: "falta de intérprete de Libras, dificuldades para impressões em Braile, ausência de programas para capacitação docente e discente". A autora conclui que a legislação sobre inclusão no Estado do Paraná representa apenas um direito positivado, com sérias dificuldades para se efetivar.

A tese de Fiorin (2018) apresenta o reflexo da ampliação do número de vagas no Ensino Superior, após a implementação do REUNI em 2007 e das ações para a permanência e conclusão nos cursos de graduação, por alunos com deficiência em universidades federais do Estado do Rio Grande do Sul. A autora conheceu os espaços, os setores e entrevistou servidores de três instituições distintas no estado do Rio Grande do Sul e apesar das diferenças entre as instituições houve uma homogeneidade quanto as ações de permanência desenvolvidas e às dificuldades enfrentadas.

Fiorin (2018) localizou nas IES investigadas os setores voltados à aprendizagem, desenvolvimento acadêmico e psicologia (SAP); os setores de acessibilidade e inclusão (SAI), essa autora destacou as ações de orientação aos professores e coordenadores quanto às adaptações necessárias para cada estudante com deficiência; setores voltados às ações afirmativas (SAF); setores voltados à assistência estudantil (SAE), com foco nos auxílios/ programas oferecidos (transporte, moradia, alimentação, creche entre outros). A autora constatou que as mudanças institucionais ainda são insuficientes frente à demanda crescente apresentada por essas políticas, pelas cotas e pelo sistema de seleção unificado e ENEM, pela necessidade de ações de acolhimento aos alunos com deficiência, a necessidade de redução das barreiras (pedagógicas, arquitetônicas, comunicacionais) que impedem a acessibilidade desses sujeitos e ações que contribuem "para a equidade de oportunidades, essenciais na produção do conhecimento e no acesso aos espaços institucionais" (GOES, 2018, p. 186). 
Dentre os trabalhos de dissertações, parte focou na política de cotas: Pereira (2007) e Rocha (2011) discutem este assunto como processo para a real inclusão a partir do seu acesso.

A dissertação de Pereira (2007) aborda a inclusão, no Ensino Superior, a partir de um estudo relacionado a alunos com deficiência que ingressaram pelo sistema de cotas, na Universidade Estadual do Rio Grande do Sul, no período de 2002 a 2005. A autora afirma que a implantação do sistema de cotas, para alunos com deficiência na Universidade, contribui para a inclusão, democratizando o acesso, em consonância com os princípios Constitucionais, na garantia dos direitos das pessoas com deficiência.

Os resultados na pesquisa realizada por Pereira (2007), evidenciaram a ocorrência de dificuldades no processo de ensino-aprendizagem e a necessidade de ações específicas para o apoio aos estudantes com deficiência.,

Rocha (2011), também discute a implementação da política de cotas para o ingresso de estudantes com deficiência no ensino superior, por meio de uma pesquisa bibliográfica e documental, considerando a insuficiência desse sistema pelas dificuldades advindas da educação básica.

O ingresso é legitimado por meio das cotas, conforme Rocha (2011), contudo ela identificou a dificuldade, porém a investigação não discutiu a necessidade de apoio para a permanência.

Já outras duas focam as pesquisas nas formas de acesso das pessoas com deficiência no Ensino superior: Sousa (2013) e Santos (2012) e a importância que este processo representa para este fim a partir das políticas desenvolvidas.

Sousa (2013), por meio de um estudo de caso, analisa a inclusão de estudantes com deficiência na Universidade Federal do Espírito Santo. O estudo realizado com a participação de gestores da Universidade e os documentos oficiais apontam que, as provas para ingresso das pessoas com deficiência na universidade são realizadas com a utilização de recursos conforme a necessidade do candidato, contudo, após o ingresso, falta infraestrutura acessível, um acompanhamento da vida acadêmica e materiais para os alunos, assim como um direcionamento para o trabalho dos professores. A autora enfatiza a necessidade de uma política institucionalizada para essa Universidade.

Santos (2012) investigou dezoito editais do processo seletivo para ingresso na graduação em Instituições de Ensino Superior na cidade de Natal - RN, com o objetivo de compreender em que medida essas instituições estão seguindo as recomendações contidas na legislação brasileira, especificamente a do Aviso Circular n 277/96 - MC/GM, no que tange às condições oferecidas aos estudantes com deficiência para o processo seletivo vestibular. A autora 
verificou que, somente dois editais apresentavam informações claras aos candidatos sobre os serviços e recursos oferecidos pela IES a quem solicita atendimento especial para a realização das provas.

Santos (2012) aponta a necessidade de cumprimento da legislação em vigor assegurando aos candidatos com deficiência o direito de concorrer no processo seletivo do vestibular, em igualdade de oportunidades, em todas as etapas, desde a inscrição até a correção final das provas.

A maioria dos trabalhos analisados tem como foco a importância da quebra de barreiras a partir da instauração de diversas ações internas nas IES que permitam a permanência dos estudantes no ensino Superior são estes: Duarte (2009); Souza (2010); Silva (2016); Luz (2018); Aguiar (2016) ou Chaiben (2019).

A garantia do acesso no ensino superior foi abordado por Duarte (2009), com a pesquisa intitulada: "A inclusão de pessoas com deficiência nas Instituições de Ensino Superior e nos cursos de Educação Física de Juiz de Fora pede passagem. E agora?” Por meio de entrevistas semiestruturadas aplicada aos coordenadores de cursos de IES privada e uma pública, o autor constatou que os estudantes com deficiência estão acessando os cursos, mas verifica a necessidade da quebra de barreiras arquitetônicas e atitudinais para o sucesso desse processo de escolarização.

O Programa INCLUIR foi tema da pesquisa realizada por Souza (2010). A autora analisou os cinco editais publicados pelo MEC entre os anos de 2005 e 2009 e os projetos de algumas Instituições de Educação Superior contempladas pelo Programa. Com o objetivo de incentivar a construção e o fortalecimento dos Núcleos de Acessibilidade nas IES, o Programa Incluir propunha melhorar o acesso das pessoas com deficiência a todos os espaços, ambientes, ações e processos desenvolvidos nas instituições. A autora identificou que das 236 IES Públicas existentes no Brasil, somente 57 tiveram projetos aprovados, representado somente $24,15 \%$ do total.

Souza (2010) constatou que a partir do edital de 2008, o foco do Programa INCLUIR passa a ser o acesso e permanência na Educação Superior e a criação e fortalecimento dos núcleos de acessibilidade. Outro movimento destacado pela autora, dos editais publicados durante os anos 2005 a 2009 do Programa INCLUIR, é a preocupação inicial em atender as políticas públicas de ação afirmativa para o atendimento à política de educação especial na Educação Superior. A autora ao analisar as ações implementadas pelas Instituições por meio do Programa INCLUIR, que tiveram seus projetos aprovados e implantaram os Núcleos de 
Acessibilidade, mostra que eles são insuficientes para garantir qualidade no acesso e, sobretudo permanência dos sujeitos com deficiência na Educação Superior.

Silva (2016) analisou as legislações que garantem o acesso de pessoas com deficiência no ensino superior e verificou in loco as práticas de inclusão em duas instituições de Educação Superior privadas em Curitiba/PR. Os resultados da pesquisa indicaram a necessidade de capacitação docente para o atendimento das necessidades dos estudantes com deficiência e a revisão das práticas institucionais para a melhoria do processo de formação acadêmica.

O direito de acesso e permanência das pessoas com deficiência ao ensino superior foi analisada por Luz (2018), por meio da análise dos processos de implantação da política de acessibilidade da Universidade Federal de Goiás e sua relação com a garantia do direito da pessoa com deficiência à educação, verificando as ações dos Núcleos de Acessibilidade das Regionais Catalão, Goiás, Goiânia e Jataí. O autor constatou a promoção do direito de acesso da pessoa com deficiência enquanto condição essencial para o alcance da dignidade e da cidadania.

A dissertação apresentada por Aguiar (2016) trata da política de Educação Inclusiva na Educação Superior da Região Sul de Santa Catarina. Com um estudo de natureza empíricodocumental, a autora analisou o PPP e o projeto Político Institucional de três instituições de ensino superior. Apesar das semelhanças e diferenças entre os documentos analisados, Aguiar (2016) reforça que a luta por instituições inclusiva requer transformações concretas no contexto das relações interpessoais e sociais. A falta de verbas e a qualificação profissional foi um dos aspectos mencionadas pela autora.

O trabalho de investigação desenvolvido por Chaiben (2019) apresenta aspectos de políticas públicas para a entrada de pessoas com deficiência em cursos de nível superior na Universidade Tecnológica Federal do Paraná - UTFPR. Por meio de análise documental e entrevista com profissionais que atuam com os ingressantes com deficiência na Universidade, o autor cita o Núcleo de Apoio às Pessoas com deficiência (NAPNE) e considera a necessidade de políticas afirmativas para a permanência desse público, apontando os desafios para docentes, servidores, prestadores de serviços, a criação de estrutura, especialmente na parte pedagógica e na acessibilidade.

Já os trabalhos de Galdino (2015); Alves (2016) e Pereira (2017) apresentam pesquisas que oferecem dados sobre o incremento das matrículas de alunos com deficiência a partir da instauração das políticas de acesso nas Universidades.

Galdino (2015) e Alves (2016) pesquisaram as políticas públicas de acesso ao ensino superior de pessoas com deficiência, analisando os dados do censo da educação básica e 
superior do Instituto Nacional de Estudos e Pesquisas Anísio Teixeira (INEP). Galdino (2015) verificou um aumento de $571 \%$ no número de alunos com deficiência na Universidade Federal da Paraíba e Alves (2016), considerou que o Programa Incluir do Governo Federal, contribuiu para os esforços empenhados pela Universidade Federal de Pernambuco para garantir o acesso e a permanência dos discentes com deficiência.

Pereira (2017) realiza a análise das políticas de inclusão e permanência na educação superior entre o público e o privado. A autora cita o programa Reuni - Programa de Apoio a Planos de Reestruturação e expansão das Universidades Federais, que financiou a construção de novos campi de Universidades Públicas, no interior dos Estados, sendo bastante criticado em virtude de "não planejamento de infraestrutura e demanda gerando um crescimento desordenado, que muitas vezes, dificultava a ocupação das vagas em alguns municípios" (PEREIRA, 2017, p. 50).

A pesquisa demonstrou que com a garantia de maior injeção de capital do Estado, quase todas as Universidades Federais aderiram ao REUNI e ampliaram a oferta de vagas para o acesso de estudantes ao ensino superior, contudo, com a diminuição de verbas públicas para as universidades, as dificuldades para garantir os padrões de excelência nos cursos oferecidos, tem sido um desafio para os reitores e professores universitários (PEREIRA, 2017).

A democratização e o acesso nas universidades federais foram sistematizados por meio do SISU/ ENEM, instituído pela Portaria Normativa no 2/2010. Pereira (2017) cita essa política pública como sendo o maior "sistema informatizado de gerenciamento do MEC para o acesso dos candidatos às vagas disponibilizadas nos diversos cursos de graduação das instituições públicas de Educação Superior" (p. 51). Após a criação do SISU, políticas como a Lei no 12.711/2012 (Lei de cotas), mencionada anteriormente e a Lei n ${ }^{\circ} 13.409 / 2016$ há, efetivamente a garantia de reserva de vagas para pessoas com deficiência nos cursos das Instituições federais de ensino. A autora apresenta o Programa INCLUIR como uma política pública de acesso e de garantia de direitos para pessoas com deficiência. Além desses, a autora cita o Programa de Financiamento Estudantil - FIES e o Programa Universidade para todos - PROUNI.

\section{Suporte para a permanência e promoção de acessibilidade}

A perspectiva da inclusão de alunos com deficiência nas instituições de ensino superior exige uma rede de suporte para a permanência e sucesso na formação acadêmica. Assim, será apresentado o estudo de duas teses e onze dissertações que refletem a realidade de instituições de ensino superior, que estão se adequando para o atendimento dos estudantes com deficiência. 
A facilitação do acesso aos conteúdos abordados nos cursos da área de biomedicina, de alunos com deficiência visual, foi tema da pesquisa realizada por Comarú (2012). Na tese foram desenvolvidas e compartilhadas ações concretas e novas metodologias de ensino para alunos com deficiência visual de graduação da área biomédica no estado do Espírito Santo. Pranchas de microscopia utilizando relevo e texturas para o ensino de histologia na graduação foram desenvolvidas como recursos pedagógico, validadas tanto para utilização por alunos com deficiência visual quanto para alunos videntes. A autora conclui que a proposta do uso de modelos pode funcionar como uma solução metodológica de acesso ao conteúdo de disciplinas morfológicas e que núcleos de apoio institucionais têm papel fundamental neste processo de inclusão.

Breitenbacha (2018) investigou a aprendizagem de alunos com deficiência intelectual na educação superior, por meio de entrevistas realizadas com profissionais que atuam no Núcleo de Acessibilidade, profissionais de apoio pedagógico, professores e coordenadores de curso. A coleta dos dados foi realizada em quatro universidades federais brasileiras: duas da região Sul, uma da região Norte e uma na Região Nordeste. Para compreender as possibilidades de aprendizagem desses estudantes, a autora ressalta a assiduidade, o fácil trato, a pontualidade, o interesse, a dedicação, a participação em sala de aula, a procura pelo professor nos momentos extraclasse e a realização de atividades extras são atitudes consideradas positivas, além da coletividade como uma possibilidade de compensação da deficiência.

O estudo desenvolvido por Breitenbacha (2018) ainda evidencia a necessidade de os docentes utilizarem diferentes estratégias para a mediação e avaliação da aprendizagem, bem como dos alunos com deficiência intelectual receberem acompanhamento extraclasse. A autora identifica como obstáculo a fragilidade das estratégias desenvolvidas para a permanência e aprendizagem desses sujeitos.

As dissertações de Santiago (2016), Ricardo (2017), Vieira (2018) e Seeger (2019) investigaram a utilização dos recursos de tecnologia assistiva como prática de acessibilidade na educação superior.

Santiago (2016) propõe a utilização de um Guia de acessibilidade na produção de materiais didáticas às pessoas com deficiência visual no ensino superior, para auxiliar professores e técnicos na adequação do material pedagógico como uma garantia de educação de qualidade e suporte necessário para os alunos com deficiência visual.

Com o objetivo de apresentar propostas de acessibilidade, tendo como base a tecnologia assistiva e o desenho universal, Ricardo (2017), investigou o perfil dos núcleos de acessibilidade das Universidades Federais, participantes do programa INCLUIR e o uso da 
Tecnologia Assistiva. A autora discutiu o Desenho Universal como um novo modelo que tem como objetivo "criar um currículo e ambientes que, pelo projeto, minimizem ao máximo as barreiras tradicionais de aprendizagem" (RICARDO, 2017, p. 194).

Com o objetivo de repensar metodologias de ensino aprendizagem de Geografia para estudantes videntes e, sobretudo, com deficiência visual, a dissertação de Vieira (2018), descreve a criação de uma tecnologia de informação e comunicação que auxilia os estudantes por meio de audiodescrição gravada de mapas do estado de Mato Grosso do Sul. Como possibilidade de construção de alternativas metodológicas para se trabalhar com pesquisadores, professores, educadores e educandos com ou sem deficiência, a autora qualificou o processo de ensino-aprendizagem em Geografia por meio do desenvolvimento de um produto acessível.

Seeger (2019) em seu estudo sobre as tecnologias assistivas para a inclusão de pessoas com deficiência no ensino superior, analisou na Universidade Franciscana de Santa Maria, RS, como ocorre a utilização dos recursos nas práticas formativas dos alunos com deficiência. Por meio da análise dos documentos do Núcleo de Acessibilidade e Inclusão e outros, e também de questionários on-line para os estudantes a pesquisa revelou que a apropriação das tecnologias assistivas encontra dificuldades quanto ao seu manuseio tanto por alunos como por professores, seja pela complexidade empregada nas tecnologias assistivas ou por necessidade de conhecimento técnico para sua utilização.

Os trabalhos de Alencar (2013), Dillenburg (2015), Ciantelli (2015), Santana (2016), Ribeiro (2016), Silva (2017) e Madruga (2019) tiveram como o foco os serviços disponibilizados para os estudantes com deficiência nas Instituições de Ensino Superior com foco nas ações dos núcleos de acessibilidade.

Alencar (2013) ao analisar a política de inclusão no ensino superior da Universidade Federal de Juiz de Fora, avaliou as ações da Coordenação de Acessibilidade Educacional, Física e Informacional, do Núcleo de Acessibilidade da Universidade, que tem como proposta promover condições de acesso e permanência das pessoas com deficiência da Instituição. A autora identificou que muitas adaptações físicas foram realizadas, por meio das ações do núcleo como a colocação de elevadores, a reserva de vagas adaptadas de estacionamento, banheiros e bebedouros adaptados.

A pesquisa de Alencar (2013) identificou obstáculos nas práticas pedagógicas dos docentes. Faltou orientação sobre as necessidades específicas dos estudantes com deficiência para o acesso ao conteúdo apresentado em aula. A maior barreira identificada pela autora foi a de acessibilidade atitudinal, que a pesquisadora cita a mudança de cultura, uma "mudança de 
preceitos muitas vezes já incutidos nas práticas e atitudes de cada um” (ALENCAR, 2013, p. 129).

A inclusão de alunos com deficiência e as ações dos núcleos de acessibilidade foram o foco da pesquisa realizada por Dillenburg (2015), ao analisar, por meio de entrevista semiestruturada com os coordenadores de cursos presenciais e à distância, o reflexo do ingresso de estudantes com deficiência nos cursos, quanto aos desafios para a acessibilidade, as ações, as incertezas e as descobertas. O direito e a legitimidade destes estudantes de acessarem os cursos foi consenso entre os entrevistados e a necessidade de adequações de acessibilidade, permanência e promoção da aprendizagem, foi identificada pela pesquisadora como sendo as ações necessárias para a inclusão.

Ciantelli (2015) analisou as ações do núcleo de acessibilidade das Universidades Federais, com foco na atuação dos psicólogos, em prol da participação de estudantes com deficiência no ensino superior. Participaram da pesquisa os coordenadores dos Núcleos beneficiadas pelo Programa Inclui no ano de 2013. A autora, por meio de estudos na área da Psicologia Social traçou o perfil das ações para a remoção das barreiras atitudinais realizadas pelos Núcleos, mesmo assunto tratado por Ribeiro (2016). Ciantelli (2015) identificou programas de sensibilização e/ou conscientização, palestras e campanhas que possibilitem a reflexão crítica sobre a importância da acessibilidade no Ensino Superior brasileiro. Assim, a autora constatou a participação do psicólogo dos núcleos de acessibilidade, mostrando-se como essencial para trabalhar com a superação da barreira atitudinal.

As estratégias e ações da Divisão de acessibilidade e ações afirmativas, da Universidade Federal do Mato Grosso do Sul, foram o foco da pesquisa realizada por Santana (2016). Por meio da análise documental, a autora considera que a disponibilização de recursos para as instituições públicas, contribuíram para a implantação dos núcleos de acessibilidade e permitiram o acesso e a permanência de estudantes com deficiência na Universidade. Conforme Santana (2016) a Universidade Federal do Mato Grosso do sul possui um Laboratório para projetos de ensino, pesquisa e extensão para atender as necessidades singulares de estudantes com deficiência.

Silva (2017) investigou os desafios da permanência de estudantes com deficiência nas Universidades Estaduais do Paraná. Por meio de levantamento bibliográfico e análise documental, sobretudo no Núcleo de Acessibilidade e nos eventos ocorridos nessas Universidades, identificou inúmeras dificuldades e barreiras enfrentadas por técnicos, docentes e especialmente pelos estudantes pela exigência de políticas de acessibilidades nessas instituições públicas. Silva (2015) ressalta os desafios, as lacunas, as barreiras e as distâncias 
entre a necessidade dos estudantes público-alvo da Educação Especial e as políticas educacionais de ensino Superior.

A pesquisa realizada por Madruga (2019) tem como foco o atendimento educacional especializado nas universidades públicas e privadas no estado do Mato Grosso do Sul, para estudantes público-alvo da Educação Especial. Por meio de entrevistas semiestruturadas para os responsáveis dos Núcleos de acessibilidade das universidades e análise documental, a autora identificou que, os espaços de acessibilidade foram organizados após a publicação do Programa Incluir, fato esse identificado na dissertação de Santana (2016).

Madruga (2019) identifica que os estudantes atendidos pelos núcleos de acessibilidade, das Universidades pesquisadas, não se restringem ao público-alvo da Educação Especial. A autora cita o atendimento para estudantes que apresentam necessidades por "questões emocionais, lacunas na aprendizagem, déficits cognitivos, entre outros” (MADRUGA, 2019, p. 159), causando tensão na área, já que o público-alvo da Educação Especial é ampliado para aqueles que apresentam transtornos de aprendizagem e/ou transtornos mentais. Madruga (2019) finaliza apontando a necessidade de mudança da cultura institucional das universidades e a necessidade de o Atendimento Educacional Especializado fazer parte do currículo de formação de professores ingressantes nas instituições de ensino superior.

\section{Percepção dos estudantes com deficiência no ensino superior}

Para compreender os avanços e os desafios com o acesso dos estudantes com deficiência no ensino superior, essa categoria de análise buscou nas pesquisas realizadas, compreender a percepção daqueles que vivenciam a inclusão. Assim foram localizadas três teses e quatorze dissertações defendidas em diferentes regiões do Brasil.

O trabalho de Rosseto (2009) buscou compreender as singularidades da trajetória pessoal e aquelas relativas à escolarização de pessoas com deficiência que frequentaram a Universidade Estadual do Oeste do Paraná - UNIOESTE. A partir do relato de suas histórias de vida, a autora analisou o processo de escolarização, o contexto familiar, a inserção profissional e a imagem a respeito de si, de quatro pessoas com deficiência, sendo um cego, um com baixa visão e dois surdos. A autora considera que as histórias de vida dos sujeitos reafirmam que:

A constituição do ser humano e suas singularidades, ainda que em condições de desvantagem, se dá sempre na relação consigo mesmo e com o outro. E, mais do que isso, que o olhar que a família e a escola dirigem ao aluno com deficiência, vai repercutir no olhar do próprio aluno sobre si mesmo, 
influenciando no seu desempenho e nas significações perante a sociedade. (ROSSETO, 2009, p. 225).

Com a mesma metodologia de trabalho, Borgmann (2016) entrevistou quatro estudantes com deficiência, matriculados em cursos de graduação e que eram assistidos pelo Núcleo de Acompanhamento e Acessibilidade Institucional na Universidade Regional do Noroeste do Estado do Rio Grande do Sul - UNIJUÍ. As interpretações das narrativas possibilitaram expressar o reconhecimento da diferença como sendo um dos grandes desafios para a inclusão dos estudantes com deficiência no ensino superior, tanto na esfera afetiva, quanto na esfera jurídica, na garantia do ingresso e permanência.

A satisfação do aluno com deficiência no ensino superior, foi o tema da pesquisa realizada por Gerreiro (2011). Por meio de um estudo de caso na Universidade Federal de São Carlos, a autora construiu um instrumento denominado: Escala de Satisfação e Atitudes de Pessoas com Deficiência - ESA, e aplicou o estudo com dezoito alunos com deficiência do campus. Os fatores estruturais e operacionais tiveram níveis baixos de satisfação, no entanto, os níveis no fator psicoafetivo e no fator atitudes foram apontados na faixa de satisfação. A autora considera necessária a aplicação de um instrumento que mensure a satisfação do aluno com deficiência no ensino superior, no sentido de avaliar as políticas institucionais e a garantia do acesso e permanência.

As pesquisas realizadas por Fortes (2005), Cruz (2016) e Sousa (2014) tiveram como foco os estudantes com deficiência visual no ensino superior.

Fortes (2005) realizou uma pesquisa em 2003, anterior ao Programa Incluir do Governo Federal, sobre a inclusão de três estudantes com deficiência visual na Universidade Federal do Rio Grande do Norte, nos cursos de Filosofia, Economia e Ciências Sociais. Por meio de entrevista identificou que a inclusão no ensino superior proporciona para os alunos com deficiência visual a superação de barreiras, como o próprio vestibular, onde não foram citadas as adaptações de acessibilidade para eles.

Além dos fatores de superação para os estudantes com deficiência visual, Fortes (2005) cita os benefícios da inclusão para os estudantes sem deficiência, com a convivência e o respeito as limitações e potencialidades daqueles com deficiência visual. A autora identifica a necessidade de formação do corpo docente e funcionários, a quebra de barreiras atitudinais e pedagógicas, e o apoio humano e material, imprescindíveis ao pleno desenvolvimento desses estudantes.

Cruz (2016), por meio de entrevista semiestruturada, aplicada individualmente com seis estudantes com deficiência visual, identificou nos resultados uma inclusão excludente, no que 
se refere à ausência de material pedagógico adaptado e barreiras arquitetônicas e atitudinais na Universidade Federal da Paraíba. A autora ressalta a conquista e os direitos das pessoas com deficiência para o acesso ao ensino superior, contudo apesar dessa perspectiva positiva, o ideal de inclusão quanto ao acesso ao conhecimento para todos ainda está longe do ideal.

Sousa (2014) realizou a pesquisa na Universidade Federal do Ceará e identificou o reflexo da política implementada após 2005, por meio da institucionalização da Secretaria de Acessibilidade, UFC Incluir. A autora teve como metodologia de trabalho a entrevista semiestruturada com sete estudantes com deficiência visual e identificou nos resultados que esses estudantes conhecem a Secretaria de Acessibilidade e a consideram como essencial para a conclusão dos estudos a cada semestre. Além de citarem os processos inclusivos para o ingresso nos cursos da Universidade, os estudantes com deficiência visual citaram como dificuldade, a relação com os professores, que comprometem a conclusão dos estudos, resultando em alguns casos reprovação de disciplinas ou até o trancamento das mesmas.

Os trabalhos de Nascimento (2011) e Passos (2016) tiveram como foco a inclusão de pessoas com deficiência no Ensino Superior, a partir da percepção das experiências vivenciadas. As autoras envolveram o público-alvo da educação especial.

Os resultados da pesquisa de Nascimento (2011) apontam que ainda é muito pequeno o percentual de matrícula de jovens com deficiência no ensino superior e que o preconceito e a falta de acessibilidade na Universidade de Recife/ PE e João Pessoa/ PB, se constituem num grande entrave para seu acesso e permanência. A autora identificou a ausência de políticas públicas e institucionais direcionadas para atender às demandas desse grupo de estudantes e a perseverança dos estudantes com deficiência para enfrentar as diversas barreiras impostas para a plena participação na vida acadêmica.

Passos (2016) também identificou uma série de limites e desafios à inclusão no ensino superior, na pesquisa de campo realizada na Universidade Federal do Mato Grosso em Rondonópolis. Assim aponta os seguintes resultados: a invisibilidade vivida em nível interpessoal e institucional; a interferência das desigualdades sociais no acesso, permanência e desenvolvimento; a distância entre a legislação brasileira e sua materialização; a falta, inadequação ou insuficiência da acessibilidade física e pedagógica, com a necessidade premente de formação e informação aos docentes e discentes, além da implementação de uma política interna mais estruturada e eficaz.

Para avaliar e identificar as dificuldades, limites e possibilidades vivenciadas pelos estudantes com deficiência no ensino superior, Tavares (2014) e Carvalho (2015) entrevistaram 
egressos com deficiência, formados nos cursos da Universidade Estadual de Maringá e da Universidade de São Paulo.

Tavares (2014) entrevistou cinco acadêmicos egressos e teve como foco o percurso escolar e a acessibilidade no ensino superior. A autora identificou como as condições de apropriação dos conteúdos escolares, a própria acessibilidade quanto as questões comunicacionais, arquitetônicas e pedagógicas, sendo a prática pedagógica diária como a grande barreira atitudinal para o acesso ao conhecimento e a ideia da homogeneização do ensino, que gera posturas de exclusão e ausência de condições de acessibilidade. Tavares (2014) ao solicitar, na entrevista com os egressos com deficiência, sugestões e recomendações às instituições de ensino superior, eles apontaram as seguintes medidas:

formação inicial e continuada de professores para a realização de mediações objetivas; a organização de instrumentos e recursos mediadores externos que garantam o acesso à instituição como um todo; ação mais efetiva dos Programas ou Núcleos de Acessibilidade e ampliação das discussões acerca de suas possibilidades de aprendizagem e desenvolvimento (TARAVES, 2014, p. 114).

Assim, Tavares (2014) ressalta a necessidade de discussões e ações fundamentadas em um entendimento da contextualização histórica e cultural acerca da exclusão.

Carvalho (2015) relata a dificuldade para localizar os estudantes com deficiência concluintes do curso de Contabilidade da Universidade de São Paulo, pela inexistência de dados disponíveis na Secretaria da Graduação e Pós-Graduação. Assim, a autora identificou o públicoalvo da sua pesquisa, por meio de relato dos professores e profissionais da instituição e realizou a entrevista com seis estudantes egressos. Os resultados do estudo demonstram que os aspectos facilitadores para o acesso ao Ensino Superior são os colegas da sala e a dificuldade identificada, apontada pela autora, é quanto a divulgação dos serviços existentes na Universidade para a garantia dos direitos das pessoas com deficiência.

Os trabalhos de Torres (2015) e Cruz (2016) tiveram a participação de estudantes com deficiência, docentes e outros profissionais envolvidos com os processos de inclusão no ensino superior.

Torres (2015) teve como objetivo investigar a prática de avaliação da aprendizagem realizada junto aos estudantes com deficiência matriculados em cursos de graduação e pósgraduação da Faculdade de Economia, Administração, Atuária, Contabilidade, Secretariado Executivo e Finanças da Universidade Federal do Ceará. As entrevistas foram realizadas com 14 pessoas, sendo 8 estudantes com deficiência. A autora identificou que houveram mudanças, contudo são primárias em relação ao que seria necessário, como a formação docente para a 
prática pedagógica com estudantes com deficiência; a inexistência de adaptações nos recursos para avaliar o estudante com deficiência de modo acessível; e a falta de conhecimento do professor das necessidades dos estudantes com deficiência quanto "às práticas avaliativas apropriadas e recursos que auxiliem o desenvolvimento do aprendizado de forma mais adequada" (p. 96).

A pesquisa realizada por Cruz (2016) contou com a presença de vinte e dois participantes, sendo cinco docentes, cinco discentes sem deficiência, cinco discentes com deficiência e cinco acompanhantes para compreender o processo de inclusão na Universidade Federal de Sergipe. Os resultados do estudo, apontados pelos estudantes com deficiência, revelam as dificuldades de acesso aos ambientes da Universidade pelas "pistas táteis soltas, incorretas ou em falta; elevadores que não funcionam; comunicação em braile incorreta nos prédios, entre outras" como uma barreira arquitetônica (p. 127). A autora destacou a inclusão de disciplinas relacionadas à formação de professor, no Departamento de Educação e Psicologia, na área da Inclusão de pessoas com deficiência e a política institucional de promover a acessibilidade educacional, por meio de acompanhantes aos alunos com deficiência.

\section{Considerações finais}

Os trabalhos apresentados discutem questões ligadas à construção de uma Instituição de Ensino Superior mais inclusiva, portanto, apesar das dificuldades apontadas e das muitas barreiras localizadas, é possível identificar o compromisso do Poder Público, com a publicação do Projeto Incluir em 2005 e a continuidade das ações nos anos seguintes, para tornar o ambiente do ensino superior mais inclusivo.

Com esse mapeamento realizado foi possível identificar ações nas diferentes regiões do Brasil e um aumento no interesse de pesquisadores pelo tema da inclusão de pessoas com deficiência no ensino superior, principalmente nas universidades federais do Brasil, já que foram essas Universidades contempladas com os incentivos do Programa Incluir.

Esse Programa fomentou a acessibilidade de jovens e adultos com deficiência nas Instituições de Ensino, democratizando o acesso e procurando romper as barreiras, identificadas em todos os trabalhos. Assim, é possível afirmar que elas existem em todas as Instituições, apesar da presença dos Núcleos de Acessibilidade e dos desafios relacionados ao investimento em recursos materiais e humanos para garantir a igualdade de oportunidade para todos.

A PN de Educação Especial na Perspectiva da Educação Inclusiva influenciou medidas e políticas institucionais, como o Atendimento Educacional Especializado para a identificação 
das necessidades do público-alvo da Educação Especial e a disponibilização dos recursos e estratégias pedagógicas. As pesquisas revelam a fragilidade da formação dos professores universitários para planejar práticas inclusivas.

A categoria de análise da percepção dos estudantes com deficiência revelou a necessidade da escuta desse público, para a implementação das políticas institucionais e do lugar de protagonista que eles podem ter, enquanto sujeitos capazes de construir um ambiente mais inclusivo.

A necessidade da formação docente e dos profissionais que atuam nas instituições de ensino superior ficou evidente nos trabalhos analisados, principalmente no relato dos jovens e adultos que, cotidianamente, são excluídos do acesso ao conhecimento pela ausência de práticas pedagógicas mais inclusivas.

O período investigado revelou o avanço da implementação das políticas públicas, após 2005 e o reflexo da trajetória de estudantes no ensino superior que enfrentam diariamente as barreiras arquitetônicas, atitudinais e comunicacionais.

\section{REFERÊNCIAS}

AGUIAR, L. C. A política de educação inclusiva nas instituições de educação superior da região sul de Santa Catarina. 2016. 131 f. Dissertação (Mestrado em Educação) Universidade do Sul de Santa Catarina, 2016.

ALCOBA, S. A. C. Estranhos no ninho: a inclusão de alunos com deficiência na Unicamp. 2008. Tese (Doutorado em Educação) - Universidade Estadual de Campinas, Campinas.

ALENCAR, P. M. M. Acessibilidade no Ensino Superior: o caso da UFJF. 2013. 151 f. Dissertação (Mestrado Profissional em Gestão e Avaliação da Educação Pública) Universidade Federal de Juiz de Fora, Juiz de Fora, 2013.

ALVES, G. C. Políticas Públicas para pessoas com deficiência: aparato legal e implementação no ensino superior. 2016. 90 f. Dissertação (Mestrado Profissional em Políticas Públicas) - Universidade Federal de Pernambuco, Recife, 2016.

BORGMANN, M. E. Reconhecimento da diferença: desafios para a inclusão dos estudantes com deficiência no ensino superior. 2016. 171 f. Tese (Doutorado em Educação) Universidade Regional do Noroeste do Estado do Rio Grande do Sul, Ijuí, 2016.

BRASIL. Câmara de Educação Básica. Parecer CNE/CEB n. 17/2001, de 03 de julho de 2001. Institui as Diretrizes Curriculares Nacionais para a Educação Especial. Brasília, DF: MEC, 2001. 
BRASIL. Conselho Nacional de Educação. Câmara de Educação Básica. Resolução CNE/CEB n. 02 de 11 de setembro de 2001. Diretrizes Nacionais para a Educação Especial na Educação Básica. Brasília, DF, 2001.

BRASIL. Constituição. Constituição da República Federativa do Brasil. Brasília, DF: Senado Federal: 1988.

BRASIL. Decreto n. 5.296, de 2 de dezembro de 2004. Regulamenta as Leis nos 10.048, de 8 de novembro de 2000, que dá prioridade de atendimento às pessoas que especifica, e 10.098, de 19 de dezembro de 2000, que estabelece normas gerais e critérios básicos para a promoção da acessibilidade das pessoas portadoras de deficiência ou com mobilidade reduzida. Brasília, DF, 3 dez. 2004.

BRASIL. Decreto n. 6.096, de 24 de abril de 2007. Institui o Programa de Apoio a Planos de Reestruturação e Expansão das Universidades Federais - REUNI. Brasília, 25 abr. 2007a.

BRASIL. Decreto presidencial n. 7.611 de 17 de novembro de 2011. Dispõe sobre a educação especial, o atendimento educacional especializado e dá outras providências. Brasília, 18 nov. 2011.

BRASIL. Lei n. 12.711, de 29 de agosto de 2012. Dispõe sobre o ingresso nas universidades federais e nas instituições federais de ensino técnico de nível médio e dá outras providências. Brasília, 30 ago. 2012.

BRASIL. Lei n. 13.146, de 6 de julho de 2015. Institui a Lei Brasileira de Inclusão da Pessoa com Deficiência (Estatuto da Pessoa com deficiência). Brasília, 7 jul. 2015.

BRASIL. Lei n. 9.394 de 20 de dezembro de 1996. Estabelece as Diretrizes e Bases da educação Nacional. Brasília, DF, 1996.

BRASIL. Medida Provisória n. 213 de 10 de setembro de 2004. Institui o Programa Universidade para TODOS- PROUNI regula a atuação de entidades beneficentes de assistência social no ensino superior e dá outras providências. Brasília, 13 set. 2004.

BRASIL. Ministério da Educação. Secretaria de Educação Especial. Política Nacional de Educação Especial na Perspectiva da Educação Inclusiva. Brasília: MEC/SEESP, 2008.

BRASIL. Programa Incluir. Documento Orientador Programa Incluir: Acessibilidade na Educação Superior. Brasília: SECADI/SESu, 2013.

BRASIL. Projeto de Lei 3627/04. Institui o Sistema Especial de Reserva de Vagas. Brasília, DF, 2004.

BREITENBACH, F. V. A aprendizagem do estudante com deficiência intelectual na educação superior: obstáculos e possibilidades. 2018. 250 f. Tese (Doutorado em Educação) - Universidade Federal de Santa Maria, Santa Maria, 2018.

CARVALHO, C. L. C. Pessoas com deficiência no ensino superior: percepções dos alunos. 2015. 95 f. Dissertação (Mestrado) - Universidade de São Paulo, São Paulo, 2015. 
CASTRO, S. F. Ingresso e Permanência de Alunos com Deficiência em Universidades Públicas Brasileiras. 2011. 278 f. Tese (Doutorado em Educação Especial) - Universidade Federal de São Carlos, São Carlos, 2011.

CHAIBEN, G. H. Políticas públicas para discentes com deficiência: a UTFPR. 156f. Dissertação (Mestrado em Tecnologia e Sociedade) - Universidade Tecnológica Federal do Paraná, Curitiba, 2019.

CIANTELLI, A. P. C. Estudantes com deficiência na universidade: contribuições da psicologia para as ações do núcleo de acessibilidade. 2015. 189 f. Dissertação (Mestrado) Universidade Estadual Paulista, Bauru, 2015.

COMARÚ, M. W. A facilitação do acesso de alunos com deficiência visual ao ensino superior na área biomédica: pesquisa para o desenvolvimento e avaliação de amteriais e métodos aplicáveis ao estudo de disciplinas morfológicas. 2012. 126 f. Tese (Doutorado em Ciências) - Fundação Oswaldo Cruz, Instituto Oswaldo Cruz, Rio de Janeiro, 2012.

CRUZ, C. L. P. Tessitura da inclusão na Universidade Federal de Sergipe: múltiplos olhares. 2016. 164 f. Dissertação (Mestrado) - Universidade Federal de Sergipe, São Cristóvão, 2016.

CRUZ, R. L. Inclusão no ensino superior: um estudo das representações sociais dos acadêmicos com deficiência visual da UFPB. 2012. 127 f. Dissertação (Mestrado em Educação) - Universidade Federal da Paraíba, João Pessoa, 2012.

DILLENBURG, A. I. Inclusão de alunos com deficiência nos cursos de graduação EAD/ UAB/ UFSM. 2015. 152 f. Dissertação (Mestrado em Educação) - Universidade Federal de Santa Maria, Santa Maria. 2015.

DUARTE. E. R. A Inclusão de Pessoas com deficiência nas Instituições de Ensino Superior e nos cursos de Educação Física de juiz de Fora Pede Passagem. E agora? 2009. 162 f. Dissertação (Mestrado em Educação Física) - Universidade Federal de Juiz de Fora, Juiz de Fora, 2009.

FERREIRA, M. E. C.; DUARTE, E. R. A inclusão de pessoas com deficiência nas instituições de ensino superior de Juiz de Fora. Juiz de Fora: Ed. UFJF, 2010. 120 p.

FERREIRA, N. S. A. As pesquisas denominadas estado da arte. Educação \& sociedade, Campinas, v. 23, n. 79, p. 257-272, 2002.

FIORIN, B. P. A. Reestruturação da Educação Superior e Ações Direcionadas à Permanência e Diplomação do Estudante com Necessidades Educacionais Especiais. 2018. 261 f. Tese (Doutorado em Educação) - Universidade Federal de Santa Maria, Santa Maria, 2018.

FORTES, V. G. G. F. A inclusão da pessoa com Deficiência Visual na UFRN: A percepção dos Acadêmicos. 2005. 243 f. Dissertação (Mestrado em Educação) - Universidade Federal do Rio Grande do Norte, Natal, 2005. 
GALDINO, I. L. A. As políticas de inclusão e as contribuições dos elementos sociais e educacionais marcantes para o acesso de alunos. 2015. 128f. Dissertação (Mestrado em Educação) - Universidade Federal da Paraíba, João Pessoa, 2015.

GARCIA, R. M. C.; MICHELS, M. H. A política de educação especial no Brasil (19912011):uma análise da produção do GT15 - educação especial da ANPED. Rev. bras. educ. espec., Marília, v. 17, n. esp. 1, p. 105-124, 2011.

GOES, E. P. Inclusão de estudantes com deficiência na Universidade Estadual do Oeste do Paraná - UNIOESTE. 2015. 255 f. Tese (Doutorado em Políticas Públicas e Formação Humana) - Universidade do Estado do Rio de Janeiro, Rio de Janeiro, 2015.

GUERREIRO, E. M. B. R. Avaliação da satisfação do aluno com deficiência no ensino superior: estudo de caso da UFSCar. 2011. 229 f. Tese (Doutorado em Educação Especial) Universidade Federal de São Carlos, São Carlos, 2011.

LUZ, K. L. B. Os caminhos da política de acessibilidade da UFG como afirmação dos direitos das pessoas com deficiência. 2018. 172 f. Dissertação (Mestrado em Direitos Humanos) - Universidade Federal de Goiás, Goiânia, 2018.

MADRUGA, R. S. O atendimento Educacional Especializado na Educação Superior. 2018. 221 f. Dissertação (Mestrado) - Universidade Federal de Mato Grosso do Sul, Campo Grande, 2018.

NASCIMENTO, V. C. de G. Quando as exceções desafiam as regras: vozes de pessoas com deficiência sobre o processo de inclusão no ensino superior. 2011. 117 f. Dissertação (Mestrado em Educação) - Universidade Federal da Paraíba, João Pessoa, 2011.

PASSOS, S. F. C. Eu e tu, nós os diferentes: a percepção dos estudantes com deficiência sobre a inclusão no ensino superior. 2016. 201 f. Dissertação (Mestrado) - Universidade Federal de Mato Grosso, Rondonópolis, 2016.

PEREIRA, M. M. Inclusão e Universidade: Análise de trajetórias acadêmicas na Universidade Estadual do Rio Grande do Sul. 2007. 201 f. Dissertação (Mestrado em Educação) - Universidade Federal do Rio Grande do Sul, Porto Alegre, 2007.

PEREIRA, S. R. C. Políticas de inclusão e permanência na educação superior: entre o público e o privado. 2017. 163 f. Dissertação (Mestrado em Educação) - Universidade Federal de Santa Maria, Santa Maria, 2017.

RIBEIRO, D. M. Barreiras atitudinais: obstáculos e desafios à inclusão de estudantes com deficiência no ensino superior. 2016. 116 f. (Mestrado em Educação) - Universidade Federal de Pernambuco, Recife, 2016.

RICARDO, D. C. Boas Práticas de Acessibilidade na Educação Superior: Tecnologia Assistiva e Desenho Universal. 2017. 215 f. Dissertação (Mestrado em Educação) Universidade Federal de Juiz de Fora, Juiz de Fora, 2017.

ROCHA, H. P. P. Política de cotas para ingresso das pessoas com deficiência nas universidades públicas e sua consonância com os preceitos da Carta Magna. 2011. 82 f. 
Dissertação (Mestrado Profissional em Políticas Públicas e Gestão da Educação Superior) Universidade Federal do Ceará, Fortaleza, 2011.

ROSSETO, E. Sujeitos com deficiência no Ensino Superior: vozes e significados. 2009. 238 f. Tese (Doutorado em Educação) - Universidade Federal do Rio Grande do Sul, Porto Alegre, 2009.

SANTANA, L. L. S. Acesso e Permanência na Educação Superior - Estratégias e Ações da Divisão de Acessibilidade e Ações Afirmativas/ DIAF na UFMS. 2016. 156 f. Dissertação (Mestrado em Educação) - Universidade Federal do Mato Grosso do Sul, Campo Grande, 2016.

SANTIAGO, J. V. B. Possibilidades e limitações nas práticas pedagógicas no ensino superior: uma análise do material didático e dos recursos de tecnologia assistiva acessíveis as pessoas com deficiência visual. 2016. 82 f. Dissertação (Mestrado) - Universidade Federal de Minas Gerais, Belo Horizonte, 2016.

SANTOS, A. S. Inclusão de Estudantes com Deficiência nas Instituições de Ensino Superior da Cidade do Natal/ RN: Análise das Condições oferecidas no Processo Seletivo Vestibular. 2012. 137 f. Dissertação (Mestrado em Educação) - Universidade Federal do Rio Grande do Norte, Natal, 2012.

SEBASTIÁN-HEREDERO, E. Currículo Inclusivo. La propuesta del DUA-Diseño Universal para el Aprendizaje. Revista de Estudos Curriculares, v. 10, n. 2, p. 39-51, 2020.

SEEGER, M. G. As tecnologias assistivas para a inclusão de pessoas com deficiência no Ensino Superior. 2019. 110 f. Dissertação (Mestrado Acadêmico em Ensino de Humanidades e Linguagens) - Universidade Franciscana, Santa Maria, 2019.

SILVA, E. A. Possibilidades, limites e desafios para a inclusão de alunos com deficiência na educação superior - legislação, reflexões e apontamentos. 2016. 96 f. Dissertação (Mestrado Profissional em Educação e Novas Tecnologias) - Centro Universitário Internacional, Curitiba, 2016.

SILVA, T. R. Desafios da permanência estudantil para a população alvo da educação especial nas universidades estaduais do Paraná: foco na UEL. 2017. Dissertação (Mestrado) - Universidade Estadual de Londrina, Londrina, 2017.

SOUSA, H. L. Para lembrar que você existe: um estudo de caso sobre as políticas de inclusão para os estudantes com deficiência na Universidade Federal do Espírito Santo. 2013. 148 f. Dissertação (Mestrado em Educação) - Universidade Federal do Espírito Santo, Vitória, 2013.

SOUSA, T. F. B. Políticas Públicas para a pessoa com deficiência na UFC: a percepção dos alunos com deficiência visual. 2014. 93 f. Dissertação (Mestrado) - Universidade Federal do Ceará, Fortaleza, 2014.

SOUZA, B. C. S. Programa Incluir (2005 - 2009): uma iniciativa governamental de educação especial para a educação superior no Brasil. 2010. 179 f. Dissertação (Mestrado em Educação) - Universidade Federal de Santa Catarina, Florianópolis, 2010. 
TAVARES, A. P. P. Educação Especial no Ensino Superior: acessibilidade no processo de inclusão escolar, a partir de relatos de acadêmicos com deficiência. 2014. 141 f. Dissertação (Mestrado) - Universidade Estadual de Maringá, Maringá, 2014.

TORRES, M. G. R. Avaliação da aprendizagem de pessoas com deficiência no ensino superior: concepções de alunos, professores e coordenadores da FEAAC-UFC. 2015. $117 \mathrm{f}$. Dissertação (Mestrado). Universidade Federal do Ceará, Fortaleza, 2015.

VIEIRA, J. M. Para ver os mapas com palavras: audiodescrição como recurso pedagógico no ensino de geografia para a inclusão de pessoas com deficiência visual. 2018. $200 \mathrm{f}$. Dissertação (Mestrado em Educação) -Universidade Federal da Grande Dourados, Dourados, 2018.

\section{Como referenciar este artigo}

LARA, P. T.; SEBASTIAN-HEREDERO, E. Organização do acesso e permanência das pessoas com deficiência no ensino superior a partir da instauração do Programa Incluir. Revista on line de Política e Gestão Educacional, Araraquara, v. 24, n. esp. 2, p. 1137-1164, set. 2020. e-ISSN:1519-9029. DOI: https://doi.org/10.22633/rpge.v24iesp2.14337

Submetido em: $30 / 04 / 2020$

Revisões requeridas em: $26 / 06 / 2020$

Aprovado em: 30/07/2020

Publicado em: 30/09/2020 